\title{
THE SEARCH FOR A CHEMICAL CURE FOR CANCER*
}

\author{
by \\ ALASDAIR B. MACGREGOR \\ I have expressed the opinion that we are at the eve of a discovery for the arrest, or perhaps, the \\ cure of cancer. (Langston Parker)
}

PARKER $^{1}$ was commenting on the treatment of cancer by chemical means in 1867 , but his words are no more nor less appropriate now than they were a hundred yearsor even a thousand years-ago.

The sophistication of cancer chemotherapy has increased with successive discoveries in the fields of medicine, biology and chemistry, but out of all proportion to the results in terms of cure or amelioration.

\section{THE FIRST DEVELOPMENTS}

The earliest known account of the treatment of cancer with a chemical substance is in the Ebers Papyrus ${ }^{2,3}$ written about 1500 B.C. It describes the use of arsenical ointments in ulcerating lesions that were probably neoplastic. In the fourth century B.C. Hippocrates ${ }^{2,3}$ recognized from his own observations that cancer was a distinctive disease. He used caustic pastes and cautery for superficial lesions, but warned that only these could be successfully treated. Celsus ${ }^{3,4}$ in A.D. 30 in De Re Medica describes the topical treatment of tumours with a variety of substances as well as excision of cancer of the breast, lip and face.

Porcius Cato ${ }^{2}$ (234-149 B.C.) used coal in the treatment of cancer and Plinius Secundus $^{2}$ (A.D. 23 or 24-79) even tried internal treatment with coal and figs. Galen ${ }^{2,3}$ the last great physician of the Graeco-Roman school, viewed cancer as a systemic disease caused by 'black bile' (atra bilis)-he used surgery, diet and purging for treatment. This is the first glimpse of an alternative view of cancer, for previously it had always been considered simply as a local lesion.

\section{THE DARK AGES}

Little is known of what happened in the succeeding seven centuries, though the early knowledge was preserved by the Church. The Arabian medical culture was active during this time, the first great figure to come to prominence was Rhazes, ${ }^{2}$ born in A.D. 860, who used an ointment containing lead and pepper for superficial lesions. Avicenna ${ }^{2,4}$ born in A.D. 980, was the first to advise the specific use of arsenic for the treatment of cancer. He also recognized the therapeutic value of music.

The Church in Europe remained a dominant factor in western medicine, being the source of teaching and guardian of manuscripts during the Dark Ages. However, it did nothing to foster the advance of medicine, and in A.D. 1215, Pope Innocent III decreed that no priest should perform any operation involving bloodshed. Thus the

* Maccabaean Prize Essay, Faculty of the History of Medicine and Pharmacy, 1966. 


\section{The Search for a Chemical Cure for Cancer}

practice of surgery was turned over to the barbers, and other groups of laymen, the most notable of whom were the 'itinerants' who wandered throughout Europe, cutting for stone, cataract and repairing hernias. Arsenic appears to have remained the specific treatment for cancer at this time; Pope Gregory $\mathrm{X}$ was treated with Frère Côme's paste (which contained a large amount of arsenic) for a facial epithelioma. It is said that there was no sign of recurrence at his death eight years later in 1276, though he suffered from arsenic poisoning during his treatment.

\section{THE LIGHT OF THE RENAISSANCE}

Theodoric of Bologna4 (who later became Bishop of Cervia) was one of the few churchmen to make his mark in medicine, and following him, the advance of medicine moved into the hands of the laity. Henri de Mondeville ${ }^{2,5}$ was the first great physician of the Middle Ages. He advised the use of arsenic and zinc chloride pastes for the treatment of superficial cancer. He was followed by Guy de Chauliac ${ }^{4,5}$ who rose from being a peasant's son to become physician to three Popes. He was an outstanding surgeon, and made considerable advances in the field of diagnosis as well as writing Chirurgia Magna which remained the authoritative text during the thirteenth and fourteenth centuries, and included a history of medicine-the first since Celsus. He also advised the use of arsenic, as a paste mixed with clay, for the treatment of superficial cancers.

The next two hundred years saw the Renaissance, with the gradual evolution of science, in medicine as well as many other fields. This period culminated in the publication in 1543 of Vesalius' work on anatomy, coincidental with Copernicus' work on astronomy. Happily for us, Vesalius' work was read and understood immediately, whereas that of Copernicus was so complex and lengthy that very few have ever read it. Ambroise Parés,4,5 was the greatest surgeon of his time (1510-90). He was strongly opposed to the use of arsenic in the treatment of cancer because of its terrible side effects, though for inoperable tumours he used diet and purgation. So too was Fabricius Hildanus ${ }^{3,4,5}$ (Wilhelm Fabry, from Hilden), who proposed instead the treatment of breast cancer by mastectomy and axillary dissection.

One of the most misunderstood and controversial figures of the time was Paracelsus $^{5,6}$ (Philippus von Hohenheim). He was strongly opposed to the use of 'Galenicals', which were mainly concoctions of various herbs, so popular at that time. He looked for the 'active principles' in drugs, and preferred chemicals to herbs in his remedies.

\section{THE CULTS OF POLYPHARMACY AND SECRECY}

Unfortunately, Paracelsus' ideas were not adopted by the medical profession, and during the following years many exotic preparations were used in the treatment of cancer. In $A$ New Practical Essay on Cancers, Burrows, in 1767, after attacking the 'establishment' describes current pathology and methods of cure, such as hemlock, night shade, antimony in various forms, mercury, caustics and bleeding, purging, diet and exercise. He then goes on to describe the marvellous results he has had from his own treatment, which he completely omits to describe. It is not surprising that some unknown hand has written 'a damned puffing quack' across the Edinburgh University 


\section{A. B. MacGregor}

copy, and later when Burrows writes of his 'anti-cancerous elixir' has added a footnote, 'so that's his famous remedy, the impudent swindler.'

The 'cure' which caused the greatest controversy was that put forward by Störck in his essay on the medicinal nature of hemlock, published in Edinburgh in 1762.7 When others failed to substantiate his results, he maintained that it was only the true Vienna hemlock which has this property. Sir John Hill ${ }^{8}$ obtained seeds of the appropriate variety, but found his results still inconclusive, and said a cure 'whether it ever will or will not be found, remains in the womb of time'. However much one may deplore Störck's methods, one must admire his literary style. His paper begins'In shady places where the soil is rich; and near ditches, and the fences of fields and meadows; grows an umbelliferous plant, which flowers in the month of July.'

\section{THE DEVELOPMENT OF THE UNDERSTANDING OF CANCER}

Advances in general, and particularly in the basic sciences were gathering momentum at this time. Harvey demonstrated the circulation of the blood, Zacharias Jans$\operatorname{sen}^{9}$ invented the microscope in 1590 - which was taken up and improved by a host of investigators including Malpighi and van Leeuwenhoek. Thomas Sydenham, the father of English medicine, was the first to prescribe iron for anaemia. Hunter ${ }^{10}$, the foremost surgeon-anatomist of the eighteenth century, discusses cancer in his Lectures on the Principles of Surgery. He differentiated between "consequent cancers in opposition to the original'. He recognized the importance of lymphatic spread which was first put forward by the Paris surgeon Le Dran (1685-1770). ${ }^{3}$ Hunter must have felt the need for a systemically active cytotoxic agent in the face of the poor results of surgery at that time, for he was moved to say, 'what I call a cure is an alteration of the disposition and the effect of that disposition and not the destruction of the cancerous parts. But as we have no such medicine, we are often obliged to remove cancerous parts; which extirpation, however, will often cure as well as we could do by changing the disposition and the action.'

At this time there was a remarkable figure, Bernard Peyrilhe. He is credited with the first attempt to transplant a tumour to an animal-the dog howled so much that his housekeeper could not bear it, and drowned the $\operatorname{dog}^{3}$ so the end result is not recorded. His treatment for carcinoma of the breast was mastectomy, with excision of pectoralis major and dissection of axillary lymph nodes. ${ }^{3,5}$ In his Dissertation académique sur le cancer, in 1776, he maintained that attempts to restore diseased tissue to normal were not only vain, but absurd. He felt the difficulty in finding a suitable chemical agent was accounted for by the similarity of normal and malignant tissue, and any agent damaging one is bound to damage the other. His ideas were in tune with those of Hunter, and show how the surgical giants of this age were already beginning to realize the immense problems involved in the successful treatment of cancer by drugs. Peyrilhe did however recommend the use of kohlsäure (carbonic acid) in the treatment of nasal carcinoma.

\section{THE PROBLEMS OF THE EARLY NINETEENTH CENTURY}

The general dissatisfaction with the methods available for the cure of cancer was reflected in the wide variety of medications that were used as an adjunct to surgical treatment. Walshe ${ }^{11}$ in 1846 gave a long list of internal and external remedies which 


\section{The Search for a Chemical Cure for Cancer}

were in common use. These included hemlock (or conium), belladonna, digitalis, antacids, tonics, alteratives (arsenic and mercury) and animal substances-animal charcoal, cod liver oil, flesh of grey lizard, which were all used as internal remedies. The external remedies in use were preparations of lead, iodine, gastric juice, carbonic acid, petroleum, tar products, turpentine, and a variety of escharotics including caustic potash, silver nitrate and arsenious acid. Rönnow ${ }^{12}$ in 1778, described the cure of 30 cases of cancer in 50 years (Mêm. Acad. roy. Sci., Stockholm, 1778) by the use of arsenic.

Sir Astley Cooper ${ }^{3,5}$ in his Lectures on Surgery in 1802 urged medical men to 'the trial of the numerous agents which chemistry and botany have, of late, abundantly discovered and simplified'. He also put forward the idea that cure by surgery should not be relied on alone, but that an attempt should be made 'to alter the constitution which has not only led to the complaint, but will surely regenerate it, if it remain unchanged'. He also realized the practical importance of lymphatic spread, and in The Anatomy of the Breast describes all the essential details of lymphatic drainage as shown by his mercury injection preparations.

In 1805, Young ${ }^{5}$ suggested the use of caustics after the excision of tumours, because he felt that it was impossible to know if any tumour cells were left.

\section{THE DEVELOPMENT OF MODERN CLINICAL INVESTIGATION}

This was a period of accelerating advance in the basic sciences, many books were published on morbid anatomy, great strides forward were being made in chemistry, Currie introduced the clinical thermometer, Auenbrugger discovered the value of percussion of the chest and Laënnec invented the stethoscope. These discoveries led to deeper understanding of disease processes, while chemistry produced a whole range of substances to investigate.

\section{THE USE OF ESCHAROTICS}

Canquoin ${ }^{1}$ in 1834 introduced the use of zinc chloride for the treatment of cancer by enucleation. He published a series of 600 cases and claimed to cure $82 \%$, compared with a $10 \%$ cure rate from excision. Rivallie' advocated the use of 'solidified' nitric acid, and Filhos' suggested the use of solid 'potassa cum calce' for treatment of cancer of the neck of the uterus in 1847. Gillespie (Edinburgh Monthly Journal, 1856) put forward the idea that such good results were obtained by the use of zinc chloride, that it should be used before surgery, rather than as an adjunct to surgery. Broadbent ${ }^{1}$ suggested the injection of dilute acetic acid into the tumour itself.

A considerable stir was caused by Dr. Landolfi, a surgeon to the army in Sicily who proclaimed the efficacy of his treatment of cancer with paste of chloride of bromide. He made a grand tour of the various leading European medical centres, modestly demonstrating his method. He unfortunately varied his treatment in different centres, sometimes adding chlorides of zinc, antimony and gold to his original paste but without fulfilling the hopes of his colleagues and his own extravagant claims. He was very strongly criticised by Lasègue ${ }^{13}$ in 1855 . Routh ${ }^{5}$ in 1866 , described the use of bromine in the treatment of two cases of cancer of the cervix.

A comprehensive survey of the position in the mid-nineteenth century was made by 


\section{A. B. MacGregor}

Langston Parker ${ }^{1}$ (1867). He discusses most of the treatments then in current use and describes which methods of treatment he feels are of value in particular situations.

\section{THE SYSTEMIC TREATMENT OF LEUKAEMIA}

Two years earlier, a paper of considerable interest was published by Lissäuer, ${ }^{14}$ describing two cases of leukaemia. The first, a woman of 32, was admitted with advanced disease of recent onset, with gross liver and splenic enlargement. Leukaemia was confirmed by the large number of white cells in the peripheral blood. At the suggestion of Dr. Rosenkranz, the chief medical officer, she was given Fowler's solution by way of experiment, because it was known that horses looked healthier and their coats glossier after being given arsenic. Despite the rather doubtful rationale of the treatment, the patient improved, and after a total of five months in hospital, was discharged. A short time after this she relapsed and died outside, and post mortem was not performed. The second case, a man of twenty, left the hospital before he could be treated. In an earlier number of the same journal, Dr. Valentiner ${ }^{15}$ had used Fowler's solution to cut short the fever in another case of leukaemia, but did not continue treatment thereafter.

\section{THE BEGINNING OF THE ERA OF SURGERY}

In the latter part of the nineteenth century the surgeon reigned supreme. Anaesthesia had relieved the immediate agonies of operation, and allowed prolonged procedures to be attempted. The discoveries of Pasteur and Lister had reduced the horrifying destruction of post-operative infection. Advances in bacteriology and pathology led to more precise appreciation of disease, while the discovery of Röentgen in 1895 opened up a whole new era of diagnostic refinement. The discovery of radium in 1898 by the Curies added a further weapon to a rapidly growing therapeutic armamentarium. Even in this rapidly changing time, Billroth, ${ }^{5}$ perhaps the leading surgeon of his period, still used zinc chloride for the treatment of superficial lesions in old, timid and anaemic patients. He also published the report of a case some years after Lissäuer's paper, on the treatment of a lymphoblastoma with potassium arsenite, which had repeated dramatic regressions. ${ }^{8}$

\section{THE DEVELOPMENT OF ENDOCRINE ABLATION}

During the last decade of the nineteenth century, the foundations were laid for two lines of attack on cancer. In 1896, Beatson ${ }^{16}$ described the effect of ovariectomy on two pre-menopausal patients with advanced cancer of the breast. He had one postmenopausal patient whom he discussed, but felt that ovariectomy should not be done. He based his treatment on observations on sheep and cows, on the effects of pregnancy on their milk production and in the knowledge of reports from abroad that ovariectomy of cows which were lactating caused them to continue their lactation. He drew the conclusion that the ovaries had some effect on the breast, which was completely independent of any neurological mediation. He obtained good early results in the two cases on which he operated. His work was followed up by a series of ninety-nine cases published by Lett ${ }^{17}$ in 1905 , with quite favourable results.

Other factors in the endocrine field were coming to light. White, ${ }^{8}$ in 1893 , had 


\section{The Search for a Chemical Cure for Cancer}

described the regression of uterine fibromas after ovariectomy, and the decrease in prostatic hypertrophy after bilateral orchidectomy. This latter finding was confirmed by several other pioneers in 1895 and 1896 . Following these precocious discoveries, there is a blank in the field of endocrine ablation in the treatment of cancer for almost forty years.

\section{THE FIRST STEPS TOWARDS MODERN CANCER CHEMOTHERAPY}

The other early move in the battle against cancer was also neglected for many years. Ehrlich, ${ }^{18}$ in 1898 , described the necrotic effects of an alkylating agent, ethylinimine, on animal epithelial tissue. Some fifty years later, this same substance was examined for its cancerocidal properties.

A curiosity of this era was the use of Coley's toxins in the treatment of cancer. ${ }^{2}$ His observations were made in 1891 and came from the observation that patients with cancer who developed erysipelas and other acute bacterial infections frequently had a remission. He, therefore, developed a toxin from the organisms and used it in the treatment of cancer. In 1909, a series was published with twenty-eight patients out of 430 surviving for five to fifteen years after treatment. However, this never became a popular form of treatment because of its severe side effects.

In 1901 , Loeb $^{19}$ published a paper describing the first successful transplantation of tumours. He used rat sarcoma which he managed to transplant from rat to rat, but not to mice, guinea pigs or hens. His work was paralleled by that of Jensen in Denmark in the same year. These discoveries were of tremendous importance in the development of an understanding of cancer, and for the assessment of cytotoxic agents.

In the early part of this century, with the improvement of micro-biological and biochemical techniques, considerable study was made of the effect of chemicals on cells. Dixon and Malden in $1908^{\circ}$ showed that colchicine had a depressant action on the bone marrow in human subjects and in 1910, Warburg ${ }^{20}$ studied the effect of phenylurethane on the fertilized eggs of the sea urchin. He showed that very low concentrations could arrest mitosis without unduly depressing the oxygen uptake. In the same year, Ehrlich's enterprise resulted in the introduction of Salvarsan for clinical use. This sparked off a tremendous drive by the German pharmacologists to find a suitable metallic compound for the treatment of cancer, so that within a few years there were a large number of drugs on the market. While undoubtedly some of these did cause necrosis of tumours in experimental animals, unfortunately clinical experience did not substantiate the optimistic claims of the manufacturers.

\section{A RETURN TO ESCHAROTICS}

In 1916, there was a renewed interest in the treatment of breast cancer with caustics, when it was realized that the results of surgery were not as good as had been hoped. Strobell ${ }^{21}$ published a paper describing his technique of destroying the skin with potassium hydroxide, while the patient was under an anaesthetic, with full aseptic precautions, and then necrosing the tumour with zinc chloride. He used skin grafts to close any large defects. He reported a series of eight cases in which he had obtained favourable results. Some months later, W. S. Stone ${ }^{5}$ reviewed the use of caustics, 


\section{A. B. MacGregor}

and came to the conclusion that it was justified to make a fresh study of their use, particularly in advanced tumours, because of the high primary mortality and the high percentage of recurrences following operation.

\section{MUSTARD GAS}

During the First World War, when an intensive study was made of all means to kill more men more quickly, mustard gas was discovered and introduced in 1917. From this inauspicious start has developed one of the most important group of drugs for the treatment of cancer to date, and which has provided the stimulus for what has now developed into one of the largest and most exciting research projects in medicine. Throughout the war years, little was known of its action, except that it was a vesicant, its action being mediated by the intracellular release of hydrochloric acid. In 1919 and 1920 , several papers were published describing its depressant action on the haemopoietic system, but apart from a few isolated studies over the next twenty years, the next advance had to await the stimulus of the Second World War.

\section{A TRIAL OF LEAD}

Shortly after the First World War, there was renewed interest in the treatment of cancer with lead, caused by the publication of a series of papers by W. Blair Bell and his colleagues of their experiences between 1920 and $1926 .{ }^{22,23}$ It all sprang from observation of the abortifacient properties of lead. They found that lead was concentrated in cells rich in phosphatides, which included chorionic epithelium, embryonic cells and malignant neoplasms. A special preparation of colloidal lead was developed and given intravenously. In $1926^{24}$ they were able to publish a series of 229 cases, of which they believed they had cured thirty-one, with the arrest of the disease process in a further ten. By this time they felt they were justified to say, 'Today we feel it is not right to prejudice any longer the method by dealing with totally helpless casescases that after trial of every known form of treatment have been sent to us in the vain hope that the day of miracles is not past.'

\section{THE DEVELOPMENT OF THE ALKYLATING AGENTS}

In 1931, a paper was published by Adair and $\mathrm{Bagg}^{25}$ which seems to have attracted little attention. They reviewed the action of mustard gas on normal skin, and then went on to examine its action on neoplasms of the skin. They proceeded from animal experiments to local application on human tumours, including epithelioma, malignant melanoma, neurofibroma and senile warts. Quite favourable results were reported, except for one patient with a malignant melanoma who died from metastases. They also tried an intratumoral injection of mustard gas to a sarcoma of the thigh. This was followed by an intense reaction, with extrusion of necrotic material through the skin, but eventually the tumour was replaced by a fibrous scar. Berenblum et al. in $1936^{26}$ showed that, in vitro, mustard gas brought about depression of oxygen consumption, and of aerobic and anaerobic glycolysis in minced tumour tissue, which was the first experimental demonstration of its anti-tumour effect.

By 1940 , so many different lines of research were being pursued simultaneously, that they are more easily followed if they are traced individually. 


\section{The Search for a Chemical Cure for Cancer}

THE DEVELOPMENT OF THE NITROGEN MUSTARDS

During the Second World War, much intensive research was done on gas warfare, one of the end results being the synthesis of nitrogen mustard, and sulphide mustard. Much work was carried out on their actions, in an attempt to develop an antidote. They were found to have, amongst their other actions, a cytotoxic effect on proliferating cells. This action was scrutinized, but was found to be quite different from the action of any known chemical, though in some respects, to be like that of radiation. The work done in this field remained secret until 1946, when Gilman and Philips ${ }^{27}$ published the results of their investigations on nitrogen and sulphur mustards. They concluded that the latter were too toxic to use clinically, but that nitrogen mustard was of potential value, though its mode of action was not fully understood. In the same year, Rhoads, ${ }^{28}$ an important contributor to the field, warned that nitrogen mustard had only so far been used experimentally on advanced carcinomas, and that it had not produced a cure of any tumour on which it had been used.

But the early results were sufficiently favourable to stimulate intensive investigations of applications for this drug, for here was a faint hope that untreatable cases might become treatable. Many series of cases were published describing its effect in many varieties of cancer. The organic chemists were also stimulated to produce an analogue which would be as effective, but easier to administer, and less toxic. It is impossible to enumerate all the compounds tested, but it is interesting to examine a few. The use of TEM (Triethylenemelamine) was described by Philips and Thiersch. ${ }^{29}$ Though it had been in use for many years in the textile industry for improving the finish of rayon fabrics, it was only discovered medically in 1950 during an intensive search for cytotoxic agents. An important group of compounds, the phosphoramides, was synthesized by the American Cyanamid Research Laboratories. Activity against rodent tumours was first described in 1951, and during the subsequent four years, a co-ordinated programme was organized to find the best analogue, the most effective dose and route of administration, and in which tumours it was of benefit. ${ }^{30}$

'Urethane' (ethyl carbamate) was, as previously noted, found by Warburg in 1910 to inhibit cell division in sea urchins. 'Phenyl urethane' and its derivatives were investigated in 1929 (Dustin et al. ( $^{31}$ and found to affect mitosis. In 1939 Lefèvre $^{31}$ described the effects of 'phenyl urethane' as being similar to those of colchicine on the roots of seedlings. This work was followed up by various authors, and in 1943, clinical trials were started in the Royal Cancer Hospital. During the next few years, many trials were carried out with it and various analogues by Haddow et al., ${ }^{31}$ but by 1950 it had virtually fallen out of use, superseded by the development of so many other chemotherapeutic agents, whose discovery it had helped to stimulate.

\section{THE CONCEPT OF THE ANTI-METABOLITE}

One of the most interesting phases of modern cancer chemotherapy arose from the concept developed by Woods ${ }^{32}$ in 1940 . He was working on the ability of sulphonamides to inhibit bacterial growth. He suggested that this was brought about by the blockage of metabolic pathways by competitive inhibition. Lewisohn ${ }^{30}$ showed that there was regression of mouse mammary tumours treated with a fermentation factor from L. casei, found later to be folic acid (Hutchings et al., 1944). ${ }^{33}$ It was synthesized 


\section{A. B. MacGregor}

in 1946 (Subba Row et al.) ) $^{34}$ and in the next year was tried in patients with disseminated carcinoma. The most interesting effect was found when it was given to the patients with acute leukaemia, when it caused stimulation of visceral and marrow cells. This was called the 'acceleration' phenomenon. The logical conclusion was drawn that a folic acid antagonist should therefore retard the leukaemic process. With the help of a drug company (American Cyanamid Company), Farber and his workers tried a series of antagonists on children with acute leukaemia. The first complete druginduced remissions were reported in 1948 with Aminopterin (4-aminopteroylglutamic acid). ${ }^{30}$ After this, laboratory studies were carried out to determine its mode of action - the inhibition of the conversion of folic acid to folinic acid is its main effect. Many other compounds have been tried, but the only effective ones are closely related to Aminopterin. It was after this work that the problem of tumour resistance became relevant, and it was found that once a tumour became resistant to Aminopterin, it was also resistant to its analogues.

This led to the first pre-planned research conducted by Hitchings and associates for an anti-cancer drug with a specific effect..$^{30}$ It had been shown that free purines may be incorporated in nucleotide synthesis, so substituted purines were synthesized. Diaminopurine was the first, but proved disappointing in use. 6-mercaptopurine was introduced in 1952 (Elion et al.). ${ }^{35}$ It was subjected to animal trials, and finally, clinical use, where it has been found to be of most value in acute leukaemia. Several analogues have been developed, but have no clinical advantage, suffer from the drawback of cross resistance, and some are positively harmful.

Following this most successful line of research, attempts were made to find other anti-metabolites for blocking other pathways, but unfortunately none of them has proved to be of any value.

\section{THE RE-DISCOVERY OF HORMONES IN RELATION TO CANCER}

A brief mention must be made of the use of steroids, as they now play an important part in the management of certain forms of cancer. As synthetic products are used, they may properly be included in this essay. Oestrogen was isolated in the late 1920s and in 1933, Dodds first succeeded in synthesizing an analogue. In 1940 Huggins et al. ${ }^{8}$ reported the results of their work on the effect of stilboestrol on the prostate of dogs, which they extended to benign prostatic hypertrophy, and finally prostatic carcinoma in man. Haddow and his associates in $1941^{8}$ also reported favourably the results of treatment of prostatic carcinoma with synthetic oestrogens.

Beatson's work on ovariectomy for carcinoma of the breast was not followed up until 1944, when Huggins and Moulder ${ }^{8}$ studied the effects of ovariectomy and adrenalectomy on dogs. Several other workers in the same year reported the results of ovariectomy in humans, while Haddow and his associates tried the treatment of advanced carcinomas with synthetic oestrogens. The initial results showed that only breast carcinoma was affected by this treatment, and even then only temporary remissions were obtained, without affecting the course of the disease.

Though these results were so disappointing, they were of great theoretical importance, because they showed that tumours could be influenced by hormones. The isolation of the glucocorticoids and ACTH in the 1940s was of tremendous significance to 


\section{The Search for a Chemical Cure for Cancer}

the whole of medicine, not least chemotherapy. ACTH was the first agent used after animal trials in 1949 by Pearson et al. ${ }^{36}$ on chronic leukaemias. In 1950 Farber et al. ${ }^{37}$ tried it on acute leukaemias, where it was found to be most effective. Since then, the synthesis of glucocorticoids has made possible an easily controllable therapy with minimal side effects, so that now steroid treatment plays a most important part in the management of acute leukaemia and breast carcinoma, and oestrogens are the most effective treatment of prostatic carcinoma.

\section{THE USE OF ANTIBIOTICS}

A fairly recent innovation has been the use of certain antibiotics. In 1940, Waksman and Woodruff ${ }^{38}$ described the inhibition of pathogenic bacteria by soil microorganisms. They studied Ps. aeruginosa and the Actinomyces. From Streptomyces (Actinomyces) antibioticus, they isolated Actinomycin, but this was thought to be too toxic for clinical use. This work seems to have been forgotten until 1949, when three different forms of Actinomycin were described by different authors. Actinomycin C is of most interest (Brockmann et al. ( $^{30}$ being strongly bacteriostatic and bacteriocidal, though very toxic. Actinomycin A was shown (Stock 1950) ${ }^{30}$ to have slight inhibitory effects on rodent sarcoma, but was too toxic for clinical use. Trials with Actinomycin C showed that it also was extremely toxic, but that it had, in some cases, a most beneficial effect in Hodgkin's disease. Waksman later developed (Manaker et al., 1954) $^{30}$ a separate, though similar antibiotic, Actinomycin D. This now has a welldefined place in the treatment of Wilm's tumour, in combination with radiotherapy. Several other antibiotics have been described, but none of them has found a place in current chemotherapy.

\section{THE TRIAL OF PLANT EXTRACTS}

Plant extracts have attracted a certain amount of attention throughout the years as a method of treating cancer. Colchicine was the first to be shown to have a definite action-depression of the bone marrow (Dixon and Malden, 1908) - $^{8}$ but it has since been found too toxic for clinical use. In an attempt to avoid the toxicity of colchicine, while maintaining its effect, Demecolcin was isolated in 1950 (Santavy and Reichstein). ${ }^{39}$ It has been found to be only effective in myeloid leukaemia, but other, less toxic, drugs are available. Vincaleukoblastine was isolated in 1958 (Coutts, Beer and Noble) ${ }^{18}$ from Vinca rosea (periwinkle). Its main effect is also on myeloid leukaemia.

One must mention, though briefly, the tremendous contribution made to this subject, by those working in the field of chemical carcinogenesis. This has opened the way for a deeper understanding of cancer, and perhaps an even more important by-product has been to make available easily reproducible tumours for experimental work. The development of tissue culture in artificial media by Eagle ${ }^{30}$ has added another most valuable tool for studying the effects of drugs on malignant cells.

\section{THE ORGANIZATION OF CONTEMPORARY RESEARCH}

A dramatic step forward was taken in 1955 in the United States of America, with the foundation of the Cancer Chemotherapy National Service Center. This was formed by the leading cancer foundations and has set out on one of the most extensive re- 


\section{A. B. MacGregor}

search programmes the world has ever seen. It has four areas of research. The first is organic chemistry, involved with the synthesis of new compounds. The second is the screening programme, which now examines in the region of 50,000 drugs a year. Those compounds which pass this screen are passed on to the third stage of pharmacological and biochemical investigation, and finally a very few reach the fourth stage of clinical investigation.

This has also served to stimulate workers all over the world and it is interesting to note how many countries have developed their own favourites in the main groups of drugs, which compare very closely in effect with each other. But no one, alas, has made a real breakthrough. The main reasons for this are that despite the rapid accumulation of knowledge and techniques, the underlying cause of cancer has not yet been discovered, and the close similarity between neoplastic and normal cells makes effective treatment difficult without damaging the host.

\section{CONCLUSION}

Is the present situation really as gloomy as this? I think not, for while the downhill course of some patients is hastened by treatment with cytotoxic agents, and many are unchanged, many have benefited over the years and though they may ultimately die from their tumours, they are enabled in the meantime to live more normal and often prolonged life. Furthermore, nearly all of the newer, effective drugs have been found as a result of empirical research, rather than scientifically planned programmes. We are not really so far removed in this search in our basic philosophy, despite all our advances, from the ancient physicians, for we still do not know the underlying cause, or causes, of cancer. Our whole concept of the disease is changing and research is branching out in many new directions. One of the most interesting from our point of view is the relationship between the tumour and the host. This varies so much for different tumours that it is possible that specific drugs will have to be developed for each one.

It is unfortunate that the pessimistic words of Burrows (1767) are still true'Although the physicians of all nations, from the time of Hippocrates to the present, have, by numberless researches and experiments, made trial of everything in nature, from the most innocent drug to the most virulent poison, both in the mineral and vegetable kingdoms; yet the disease still baffles the power of physic'. But if progress is to be made, we must take courage from Walshe (1846) who, writing on the cure of cancer by drugs, said '. . . nothing can be more unphilosophical than to conclude that it does not exist, because it has not yet been found.'

\section{REFERENCES}

1. Parker, Samugl William Langston, The Modern Treatment of Cancerous Disease by Caustics or Enucleation, London, John Churchill \& Sons, 1867.

2. Heller, J. R., Bull. N.Y. Acad. Med., 1962, 38, 348.

3. HaAgensen, C. D., Amer. J. Cancer, 1933, 18, 42.

4. Guthrie, Douglas, A History of Medicine, Edinburgh, Thomas Nelson, 1945.

5. Stone, W. S., New York Medical Record, 1916, 90, 628.

6. WALKER, J., Brit. med. Bull., 1947/48, 5, 361.

7. Essay on the Medicinal Nature of Hemlock, Edinburgh, 1762. 


\section{The Search for a Chemical Cure for Cancer}

8. HADDOW, A., Brit. med. Bull., 1946/47, 4, 417.

9. Encyclopaedia Britannica.

10. DoBson, J., Ann. roy. Coll. Surg. Engl., 1959, 25, 176.

11. WALSHE, W. H., The Nature and Treatment of Cancer, London, 1846, pp. 193-220.

12. HadDOw, A., 'The contribution of Chemistry to cancer research', in Chemistry in the Service of Medicine, ed. F. N. L. Poynter, London, Pitman, 1963, pp. 117-130.

13. Lasègue, C. L., Dublin J. med. Sci., 1855, $20,481$.

14. LISSAUER, H., Berl. klin. Wschr., 1865, $2,402$.

15. VAlentineR, W., Berl. klin. Wschr., 1865, 2, 320.

16. Beatson, T. G., Lancet, 1896, ii, 104.

17. LETT, H., Lancet, 1905, i, 227.

18. HART, G. D., Canad. med. Ass.. J., 1962, 86, 575.

19. LOEB, L., J. med. Res., 1901, 6, 28.

20. WARBURG, O., Z. physiol. Chem., 1910, 66, 305.

21. Strobell, C. W., New York Medical Record, 1916, 90, 271.

22. Blair Bell, W., Lancet, 1922, ii, 1005.

23. BlaIR BeLl, W., Lancet, 1925, ii, 1003.

24. Blair Bell, W., Woolfenden, H. F., Williams, W. R., Cunningham, L. and Herd, S. B., Lancet, 1926, i, 537.

25. AdaIR, F. E. and BAGG, H. J., Ann. Surg., 1931, 93, 190.

26. Berenblum, I., Kendall, L. P. and ORR, J. W. Biochem. J., 1936, 30, 709.

27. Gilman, A. and Philips, F. S., Science, 1946, 103, 409.

28. RhoAds, C. P., J. Amer. med. Ass., 1946, 131, 656.

29. Phimips, F. S. and ThIIRsCh, J. B., J. Pharmacol. exp. Ther., 1950, 100, 398.

30. Farber, S., Toch, R., Sears, E. M. and Pinkel, D., Advanc. Cancer Res., 1956, 4, 1.

31. Haddow, A. and Sexton, W. A. Nature, 1946, 157, 500.

32. BODLEY SCOTT, R., Brit. med. J., 1958, i, 1.

33. Hutchings, B. L., Stokstad, E. L. R., Bohonos, N. and Slobodkin, N. H., Science, 1944, 99, 371.

34. Angier, R. B., Boothe, J. H., Hutchings, B. L., Mowat, J. H., Semb, J., Stokstad, E. L. R., Subba Row, Y., Waller, C. W., Cosulich, D. B., Fahrenbach, M. J., Hultquist, M. E., Kuh, E., Northey, E. H., Seeger, D. R., Sickels, J. P. and SMTTH, J. M., Science, 1946, 103, 667.

35. Elion, G. B., Burgi, E. and Hrtchings, G. H., J. Amer. chem. Soc., 1952, 74, 411.

36. Pearson, O. H., Eliel, L. P., Rawson, R. W., Dobriner, K. and Rhoads, C. P., Cancer, 1949, $2,943$.

37. Farber, S., Shwachiman, H., Toch, R., Downing, V. H., Kennedy, B. H. and Hyde, J., Proc. 1st. Clin. A.C.T.H. Conf., 1950, p. 328.

38. Waksman, S. A. and WoOdRuFF, H. B., J. Bact., 1940, 40, 581.

39. Santavy, F. and Reichstein, T., Helv. chim. Acta, 1950, 33, 1606. 